\title{
La dialéctica entre lo uno y lo múltiple. El sufismo de Ibn 'Arabi en la narrativa de Mario Bellatin
}

\author{
Tÿl Nuyts \\ University of Antwerp
}

\begin{abstract}
Recuerdo la primera vez que vi la ilustración de una danza sufí. Se trataba de la fotografía de un derviche girador en pleno proceso de oración. Era impresionante observar la milésima de segundo en el que la imagen había sido captada. En la representación la silueta del derviche, a pesar de encontrarse presente, había casi desaparecido. Lo único que se podía apreciar era la estela fugaz de un movimiento sin fin.
\end{abstract}

-Mario Bellatin, Underwood portátil. Modelo 1915

El motivo del derviche girador, el sufí que gira alrededor de su eje en la búsqueda de la verdad divina, está omnipresente en la obra de Mario Bellatin. En Disecado, una novela onírica en la que el narrador conversa con su propio 'yo' en el borde de la cama, ese 'yo' relata que incursionó en un "camino espiritual: el sufismo [...] con el fin de que sus dudas literarias fueran respondidas de una manera definitiva: nada menos que a través de la mística" (216). La idea de que el sufismo sea capaz de ofrecer respuestas a preguntas acerca del oficio literario encuentra ecos en muchos de los textos del escritor mexicano. En Underwood portátil. Modelo 1915, un manifiesto digresivo que pretende despejar los misterios acerca de la poética de Bellatin, el narrador que se parece mucho al propio Bellatin, considera los ritos que se realizan en la tekke, la mezquita sufí a la que asiste, como "similares a las desordenadas palabras que surgen cuando busc[a] crear textos con una cierta coherencia" (504). En Escribir sin escribir, a su vez, un texto metapoetical leído a menudo por el autor como discurso, se sostiene que la escritura busca "el punto donde 
se abren todas las posibilidades", lo cual genera el reconocimiento de que "no queda otro recurso sino el de cobijarse bajo un orden trascendente" (12). Por tanto, se considera el proyecto literario como "cercano a la experiencia mística, en la que [...] se encuentra el infinito y quizá la profecía” (12).

La presencia del sufismo, rama mística del Islam, en la literatura latinoamericana puede parecer algo insólita. Aunque autores como Jorge Luis Borges, Octavio Paz y Alberto Ruy Sánchez se han referido al sufismo en sus textos, en ninguna obra latinoamericana esa práctica islámica goza de una presencia tan destacable como en la de Mario Bellatin. ${ }^{1}$ Como el Islam no tiene mucha visibilidad en Latinoamérica, no todos los lectores de la obra del escritor mexicano estarán familiarizados con el sufismo. ${ }^{2}$ Esa rama mística del Islam consiste en la enseñanza esotérica centrada en la contemplación de Dios. Como término, refiere a un abanico de ritos y hermenéuticas diversos que juntos forman la mística islámica (Ohlander 2015: 54). Una característica común es que todo sufí intenta llegar a una experiencia directa con su creador, lo cual solo puede lograr siguiendo un recorrido espiritual guiado por un shaykh, un guía espiritual (Bize 2016: 56, Ridgeon 2015: xv). El proyecto del sufismo se explica a menudo mediante la metáfora de la almendra. Según esa metáfora, la cáscara representa el aspecto exterior o exotérico de la religión musulmana; es la ley revelada, la sharia, a la que el sufí, como todo musulmán, obedece. Debajo de la cáscara se encuentra la tariqa, el camino espiritual del sufismo, o los ritos esotéricos emprendidos por el sufí con el fin de llegar al núcleo de la almendra, la haqiqa, la verdad divina encarnada por Dios (Ohlander 2015: 61).

Menciones al sufismo no solo abundan en las obras de Bellatin, sino que también aparecen repetidas veces en el discurso público del escritor. En entrevistas y en entradas en los medios sociales, el autor se describe a sí mismo como un converso al Islam, un monje sufí y un miembro de la Comunidad El Nur-Ashki-Yerráhi ubicada en México D.F. ${ }^{3}$ En su cuenta de Facebook, Bellatin, que casi siempre va vestido de un hábito sufí, comparte enlaces a vídeos de derviches de la orden Mevlevi en Estambul y de la shaykha de la mezquita sufí a la que asiste. ${ }^{4}$ En entrevistas, explica que su conversión al Islam y el espacio místico que esa le permitió conocer constituyeron la mejor escuela de creación que pudiera haber tenido. 5 Según el autor, su decisión "de realizar [...] una práctica espiritual cambió por completo [su] relación con la escritura” (Neyra 2012: 215). En concreto, su aprendizaje de las enseńanzas esotéricas del sufismo provocaron un cambio absoluto respecto a su libertad artística: "Before I met the Sufi group [...] my work was in some way framed within how traditionally literary artistic things should be. Once [...] I entered Sufism - it was like I broke the limits."5

A pesar de la presencia del sufismo en la obra de Bellatin, la mayoría de los estudios ha hecho caso omiso del aporte que le da a su obra el pensamiento sufí, al cual solo se le menciona de paso, considerándolo como una curiosidad juguetona que se inserta en las novelas con el propósito de desorientar al lector, hechizándolo con elementos que le son ajenos (Palaversich 2003). Muchos estudios destacan que las alusiones a símbolos sagrados que abundan en la obra de Bellatin, la mayoría referentes al sufismo, son en su mayoría "burlescas e irónicas" (García Caballero 2011: 30). No obstante, un indicio de la importancia del sufismo para la comprensión de la narrativa de Bellatin es el hecho de que figuren las entradas "Derviche girador" y "Islam/sufismo" en el reciente Abecedario Bellatin 
(Arías 2017, Vecchio 2017), con la mención de que la novela autoficcional El Gran Vidrio "lleva estampado [...] la marca del Islam, bajo uno de sus movimientos místicos, conocido con el nombre de sufismo" (Vecchio 2017: 394). La relevancia de la mística islámica para la obra de Bellatin se ve afirmada además en un estudio que postula que la celebración sufí es una "metáfora ideal para explicar el funcionamiento externo e interno de sus narraciones" (Martínez 2011: 238).7 Sin embargo, aunque se ha apuntado que Bellatin escribe para preguntarse "qué tipo de novelas surgirían de [...] códigos religiosos o místicos" (López Alfonso 2015b: 59), no se ha profundizado en la presencia de esos códigos en su narrativa. Puesto que las lecturas que sí señalan el aspecto religioso de la obra del escritor mexicano no comentan el sufismo en detalle (López Alfonso 2013, 2015a; Martínez 2011) o proponen una lectura metaliteraria que se basa en una concepción básica de la mística islámica exenta de conceptos teológicos (Pitois-Pallares 2015), parece oportuno ańadir otra perspectiva: una que aborde la obra de Bellatin a través de los conceptos de un pensador sufí concreto, en vez de restarles importancia por su carácter extranjerizante, meramente decorativo o exento de carga teológica.

Este artículo aspira a arrojar luz sobre las maneras en que la obra de Bellatin dialoga con el pensamiento del pensador sufí Ibn 'Arabi. Basándose en siete textos del escritor mexicano, el análisis examinará la manera en que su narrativa se apropia de dos conceptos de Ibn 'Arabi. Cabe advertir que en su investigación del funcionamiento de la mística islámica en la narrativa de Bellatin, no se pretende aportar un análisis exhaustivo de los textos bajo consideración, sino más bien demostrar cuán arraigados están los conceptos sufís en la obra de Bellatin, por una parte, y analizar la función literaria de dichos conceptos en esa obra, por otra. Por tanto, para el siguiente análisis no importan las verdaderas creencias del propio Bellatin: se investigará cómo su literatura se alimenta de conceptos provenientes del pensamiento sufí. Así, se demostrará que la finalidad de la apropiación del sufismo en la narrativa bellatiniana consiste en crear una obra que aspira a la totalidad desde una dialéctica entre lo uno y lo múltiple.

\section{La totalidad en la narrativa de Bellatin}

La razón principal por la que la mayoría de los estudios sobre las novelas de Bellatin no ha profundizado en las relaciones entre su narrativa y el sufismo se encuentra en la muy difundida convicción de que la obra de Bellatin niega toda idea de totalidad. Muchos estudios consideran el sufismo tal y como aparece en las novelas del escritor mexicano como solo uno entre muchos elementos temáticos que marcan sus obras: entre otros, las prótesis, los perros, las enfermedades y las referencias a un escritor con el nombre de Mario Bellatin. Según la mayoría de los autores, estos motivos recurrentes son meros símbolos vacíos, zanahorias que sirven para seducir al lector, a quien se le da con "la puerta en las narices" (Luna 2011: 307-308). Estos autores parecen coincidir en que la obra de Bellatin "enfatiza la dispersión de elementos" sin "revelar grandes verdades" (Epplin 2012: 111-112) con el fin de "provocar extrañamiento en el lector" (López Alfonso 2015b: 25). Así, las novelas "tiende[n] trampas textuales que prometen el desciframiento del sentido" y aunque admiten una multitud de interpretaciones, "ninguna de ellas combina en un todo coherente varios hilos narrativos" (Palaversich 2003: 31, 25). De manera posestructuralista, se sostiene que los textos de Bellatin constituyen una narrativa que 
"no puede ser comprendida en su totalidad, ya que lo único que es considerado 'real' es el discurso" (Martínez Caballero 2011: 13) y que ese discurso consta de un "lenguaje que des-significa” (Saénz 2012: 149).

Sin embargo, en la obra de Bellatin pueden encontrarse indicios que las novelas aspiran a una totalidad que supera la fragmentación y que, como veremos más tarde, difiere de la concepción de la totalidad como la entienden la mayoría de los estudios sobre la obra del escritor mexicano. Tomemos por ejemplo el siguiente pasaje del texto metapoético $E l$ registro de las flores, donde el narrador afirma que lo que le fascina al escribir es

el hecho de ver aparecer una letra, luego otra, después la palabra completa. Un ejercicio casi físico, cuyo goce está presente ya desde la posibilidad de ir admirando cómo una página va dejando de ser un espacio vacío. Un placer [...] que en el camino va dejando una serie de obras dispersas que, curiosamente, a pesar de su aparente desarticulación, forman un todo. (268)

Esta aspiración a la totalidad ha sido advertida por el escritor argentino Alan Pauls, quien apuntó que las novelas de Bellatin, que muchas veces recuperan motivos o incluso partes literales de sus propias novelas, están en busca de la obra total: "[e]s como si la Obra ya hubiera sido concebida, una obra inmensa, oceánica, sin forma ni límites, y ahora, para escribirla, Bellatin se limitara a volver a ella como a [...] un archivo, y a [...] recortar los momentos que después se publicarán en forma de libros" (citado en López Alfonso 2015b: 16-17). Siguiendo ese razonamiento, Vittoria Marinetto entiende la obra de Bellatin como un palimpsesto compuesto por novelas que "acaban con-formando un todo como si participaran de un único libro que se sigue autogenerando" (2012: 16-17). Prestando su terminología del narratólogo Gérard Genette, Martinetto sostiene que la narrativa de Bellatin es esencialmente 'hipertextual': se basa en otros libros (2012: 21). A diferencia de la mayoría de la literatura hipertextual, sin embargo, la de Bellatin no se basa en libros de diferentes autores sino del mismo autor, "en un círculo vicioso y autosuficiente" (Marinetto 2012: 21). Según Martinetto, esta hipertextualidad evidencia que la narrativa bellatiniana remite a un "misterioso hipotexto cuya naturaleza no será nunca revelada" (Martinetto 2012: 22). Aunque Marinetto se limita a rastrear las estrategias hipertextuales en la obra de Bellatin sin profundizar en la naturaleza de ese hipotexto o 'todo' inaprensible, su análisis parece sugerir que la obra bellatiniana no consta de fragmentos narrativos sueltos sino que remite a una concepción muy particular de la totalidad.

Esto se ve confirmado en el artículo "Micrometanarratives and the Politics of the Possible" de Adam Morris, donde se observa que Bellatin "enact[s] the loss of narrative by replacing it - paradoxically - with a personal web of narratives that govern the closed textual network of their literary production” (2011: 93). Esa red textual está compuesta de lo que Morris llama micrometanarratives: narrativas que no tienen el mismo estatuto que los metarrelatos totalitarios de antaño, pero que, por mínimos y fragmentarios que sean, buscan unirse para formar un todo elusivo (2011: 93). En su lectura de la obra de Bellatin, Morris apunta que la función de los signos dispersos que vuelven una y otra vez en las novelas del autor mexicano funcionan como conexiones entre las obras. Estos signos resisten la interpretación a nivel de la novela individual en la que aparecen: "[r]eaders that 
attempt to decipher these signs as keys to the meaning of a text will be frustrated because individually these symbols do not necessarily mean anything." (Morris 2011: 99). No obstante, el hecho de que vuelvan a aparecer los mismos motivos con una frecuencia tan alta hace que el lector, a medida de que vaya leyendo más obras del autor, vaya vislumbrando una coherencia: "the more seasoned she becomes, the more she will begin to understand the coherence of the works as a whole through the accumulation of signs that accrue meaning through repetition and codification in the symbolic system" (Morris 2011: 101). El resultado es que cada obra, e incluso cada elemento formando parte de ella, constituye "a connection between works created at different moments, a metareferential link within the larger Work" (Morris 2011: 105-6).

Curiosamente, no se relaciona el afán por la totalidad en la obra de Bellatin con las referencias al sufismo en su narrativa, mientras que esa rama mística atribuye los orígenes de todos los fenómenos a una totalidad única que, según la doctrina islámica, es Dios. Es llamativo en este respecto que Martinetto, al describir las relaciones entre las novelas del escritor mexicano, utiliza el término "transcendencia textual" como sinónimo de la hipertextualidad, sin indagar en la resonancia religiosa de ese término (2012:21). De acuerdo con ese significado religioso, se puede entender el sufismo como una micrometanarrativa que apunta a una obra bellatiniana total y transcendente. Así, se observa que la actividad metarreferencial o hipertextual de su obra va más allá de la mera coherencia textual, y que la noción de la transcendencia textual está inextricablemente relacionada con la de la transcendencia religiosa. Por tanto, el siguiente análisis argumenta que el sufismo no funciona como una micrometanarrativa cualquiera en la obra de Bellatin, sino como una micrometanarrativa fundamental para la construcción de su narrativa. Así, los argumentos de Martinetto (la obra de Bellatin apunta a un hipotexto elusivo) y de Morris (la obra de Bellatin remite a una totalidad compuesta por sus micrometanarrativas) encuentran una caja de resonancia en el pensamiento de uno de los pensadores sufís más importantes: el de Muhyiddin Ibn 'Arabi.

\section{La inmanencia y transcendencia simultánea}

Cuando se le preguntó en una entrevista qué libro sobre el sufismo recomendaría, Bellatin sugirió El Tratado de la Unicidad de Ibn 'Arabi.' Muhyiddin Ibn 'Arabi (1165-1240), también conocido como el Shaykh al-Akbar, el 'maestro más grande', es sin ninguna duda uno de los pensadores que más influencia ha tenido en la mística islámica (Ridgeon 2015: xv). Ibn 'Arabi fue un pensador a quien se le ha caracterizado como un místico sufí, un estudioso de la ley islámica y un filósofo neoplatónico (Bize 2016: 56, Almond 2004: 12-13). Puesto que su vasta obra admite un sinfín de lecturas, su pensamiento ha sido relacionado con corrientes como la mística cristiana, el taoísmo y el New Age, así como con pensadores como Meister Eckhart, Kant y Derrida (Hirtenstein 1999: 5, Almond 2004: 1). A lo largo de su vida, Ibn 'Arabi escribió más de 350 volúmenes y tratados que aspiraban a abordar toda la enseñanza espiritual del islam.

Es fundamental para el pensamiento islámico la doctrina de tawh.ìd (unicidad), la cual afirma la unicidad de Dios. Como religión monoteísta, el Islam postula que Dios es uno y único, y por tanto radicalmente diferente de su creación, como reza el verso del Corán: "No hay nada que se le asemeje" (C. 42:11) (Hirtenstein 1999: 256). Ibn 'Arabi 
sostiene que el significado verdadero de tawh.ìd es un misterio para el ser humano ya que "el aspecto no manifiesto de Allāh [...] es completamente inasequible y trasciende cualquier concepto, definición o categoría” (Mora Zahonero 2016: 32). Para Ibn 'Arabi, es imposible entender a Dios utilizando la razón, lo cual para él equivaldría a intentar domesticarlo (Almond 2004: 12). ${ }^{8}$ Por consiguiente, ha dedicado toda su obra a la circumambulación alrededor de un Dios que está más allá de todas las descripciones (Hirtenstein 1999: 6,18).

El concepto del wah.dat al-wujūd ocupa un lugar central en el pensamiento de Ibn 'Arabi y remite a la unicidad del ser. Ese concepto basado en la noción clave de tawh. id refiere a la idea de que Dios, aunque único e indivisible, se manifiesta en todos los grados de la creación (Hirtenstein 1999: 26). Por consiguiente, todos los fenómenos de la existencia de los que la creación está compuesta son lugares de manifestación que expresan la unicidad divina que les ha originado (Mora Zahonero 2016: 39, Hirtenstein 1999: 19, 26). Formulado de otra manera, según Ibn 'Arabi y las ramas del sufismo que se han inspirado en sus escritos, Dios se manifiesta en el mundo bajo un sinfín de formas, sin hacerse múltiple él mismo; de esta manera "contagia de singularidad [...] a cada esfera de existencia” (Mora Zahonero 2016: 39). Ya que según ese marco teológico todo ser individual proviene del mismo origen divino, el objetivo de la existencia humana es realizar su origen, embarcándose en un retorno gradual ascendiente a Dios mediante una serie de estaciones espirituales (Almond 2004: 12).

De todo esto se desprende que el proyecto de Ibn 'Arabi consiste en atribuir los orígenes de todos los fenómenos a la totalidad única que, para él, es Dios. Al mismo tiempo, se preserva la individualidad ontológica de todos los componentes de la creación (Almond 2004: 14). Puesto de otra manera, Dios es transcendente e inmanente a la vez. Es transcendente ya que es un creador que está más allá de lo relativo y lo encarnado, y por tanto fundamentalmente incomprensible para la mente humana. Pero al mismo es inmanente, dado que se manifiesta en todas las formas presentes en la creación, sin que la suma de estas formas le pueda definir (Almond 2004: 9, Hirtenstein 1999: 21). Estas ideas equivalen a decir que Ibn 'Arabi reconoce la simultaneidad de lo inmanente y lo trascendente.

El reconocimiento de esa simultaneidad tiene por implicación importante que para Ibn 'Arabi todas las religiones tienen un elemento de validez: todas son manifestaciones de una sola verdad inasequible y forman intentos de acercamiento a un Dios que está fuera del alcance de cada proposición que intenta definirlo (Hirtenstein 1999: 67, Almond 2004: 15). Por analogía, el Corán, como verdad revelada del islam y síntesis de revelaciones anteriores, puede interpretarse de muchas maneras diferentes. Puesto que todas las interpretaciones posibles han sido originadas por su creador, cada una se considera legítima: cada lectura es una manifestación inmanente de una verdad única y transcendente (Almond 2004: 69).

Para mejor apreciar la manera en que el pensamiento de Ibn 'Arabi funciona en la obra de Bellatin, es preciso señalar que algunos autores han advertido semejanzas entre el pensamiento akbarí y la desconstrucción. En su estudio de las similitudes entre el pensamiento de Ibn 'Arabi y el de Jacques Derrida, Ian Almond ha investigado, entre otras cosas, las semejanzas entre la idea akbarí de que la verdad divina solo se deja vislumbrar parcialmente por las manifestaciones, y el concepto derrideano de la différance, que postula que el significado de un texto no se puede captar con la razón humana ya que siempre se 
pospone, produciendo así una red de significaciones (2004: 36-37). Sin embargo, a pesar de sus semejanzas, los dos pensamientos difieren en un punto importante:

Whereas for Ibn 'Arabi it is infinite presence which causes the text to multiply and proliferate - the infinite presence of God in all interpretations - for Derrida it is an infinite absence which gives the text its freedom. (Almond 2004: 76)

Para Ibn 'Arabi, la creación, constituida por las formas inmanentes que apuntan a la transcendencia única de su creador inalcanzable, encuentra un eco en las 6236 aleyas del Corán que abarcan todos los significados e interpretaciones posibles, refiriéndose a la verdad única e incomprensible de Dios y siendo al mismo tiempo originadas por ella. El posestructuralismo, en cambio, conceptualiza el aplazamiento del significado como desembocando en un vacío (Almond 2004: 15). Si para Derrida, la naturaleza anárquica del texto socava todo tipo de sistema totalitario, para Ibn 'Arabi, toda interpretación del Corán tiene por fin de reforzar la unicidad del texto revelado: "if texts for Derrida threaten to disrupt unity, for Ibn 'Arabi they serve to express it" (Almond 2004: 71).

Se ha observado que la mayoría de los estudios de la obra bellatiniana la leen en clave posestructuralista, enfatizando las maneras en que su narrativa resalta la incapacidad de la ficción de expresar una verdad (Carlsen 2015: 67). No obstante, una lectura posestructural difícilmente puede captar que la obra de Bellatin "no plantea la nada [...], quizá por la predisposición espiritual del propio autor" (Mora 2012: 85). Efectivamente, aunque un enfoque posestructural "probably fall[s] in line with the author's own concept of his writing", corre el riesgo de excluir otras interpretaciones posibles si se limita a abordar la obra de Bellatin de esta manera (Carlsen 2015: 67). A pesar de que el sufismo recibe un tratamiento hasta cierto punto lúdico en muchas de las novelas del escritor mexicano, este artículo demostrará que las referencias a la mística islámica son funcionales para la poética de Bellatin. Por tanto, este análisis sostiene que las interpretaciones de la obra de Bellatin que se han limitado a leer las configuraciones de la totalidad en clave posestructuralista se pueden enriquecer mediante una concepción más matizada de la totalidad: una que enfoca las relaciones entre lo uno y lo múltiple, y el acto creativo que los conecta. Es lo que demostraremos a continuación.

\section{Círculos alrededor de la totalidad}

Es llamativa la semejanza entre la noción akbarí de wah.dat al-wujūd y el concepto de las micrometanarrativas mencionado anteriormente. Leyendo la obra de Bellatin a través del concepto de wah.dat al-wujūd, cada micrometanarrativa o elemento narrativo disperso puede entenderse como una forma inmanente. Así, siguiendo a Ibn 'Arabi, se puede leer esta forma, como "cada fenómeno" de la creación, como "una aleya, un signo, un dedo que apunta hacia el acto creador del que proceden todas las cosas" (Mora Zahonero 2016: 52). De ese modo, puede observarse que en la obra de Bellatin la noción de wah.dat al-wujūd se pone en práctica tanto a nivel intratextual como intertextual.

A nivel intratextual, los elementos dispersos de la narrativa de Bellatin buscan unirse para llegar a formar un todo que les supera. En la novela corta Flores, por ejemplo, se 
juntan una serie de capítulos breves que todos llevan el nombre de una flor y que son protagonizados por diferentes personajes cuyos itinerarios fragmentarios nunca se cruzan. ${ }^{10}$ Aunque el preámbulo plantea que "cada capítulo pueda leerse por separado, como si de la contemplación de una flor se tratara" (261), juntos estos capítulos forman un ramo que queda últimamente inasible para el lector. Así, "la suma de [...] objetos que juntos conforman un todo" (261) se sustrae a la vista pero sigue presente de manera implícita, como la promesa de una totalidad inalcanzable.

Algo similar ocurre en El Gran Vidrio, novela autoficcional que lleva el oxímoron 'tres autobiografías' como subtítulo y donde la identidad de los sucesivos narradores se desplaza perpetuamente hasta que se hayan retratado "tantos bellatines como autobiografías" (López Alfonso 2015b: 61). El yo, que pretende escribir una auténtica autobiografía, aparece en la primera parte como un niño encerrado en una institución mental. En la segunda parte, se transforma en un escritor mexicano convertido al sufismo, para entrar en escena en la parte final como una niña delgada de cuarenta años que se transforma primero en una mujer gorda y luego en un escritor llamado "Mario Bellatin". Al final de la tercera parte, el narrador-autobiógrafo encuentra su identidad definitiva al convertirse en Abdus al-Salam, el Hijo de la Paz. ${ }^{11}$ En ese momento, el yo pseudoautobiográfico admite que "difumin[a] lo más que se pueda una identidad determinada", y que trata de cambiar "de tradición, de nombre, de historia, de nacionalidad, de religión" con el propósito de que "el texto se manifieste en cualquiera de sus posibilidades" (164). Según una "lógica de zapping que va de una identidad a otra" (Saénz 2012: 158) el amalgamo en mutación que se presenta como narrador reivindica la cohabitación de múltiples identidades como parte esencial de un proyecto que va en busca de la totalidad existencial. Aunque podría argumentarse que este desplazamiento de identidades se alimenta del concepto derrideano de la différance, El Gran Vidrio invita otra lectura. Efectivamente, se puede concebir "la unicidad del ser" no como "perdida", como la entiende Palaversich (2003: 33), 12 sino como afirmada radicalmente. Al igual que las obras dispersas que buscan formar un todo en El registro de las flores (véase arriba), el ramo compuesto de flores narrativas en Flores, y los muchos temas y personajes que vuelven repetidas veces a lo largo de la obra de Bellatin, la suma de los cambios en las identidades sucesivas de la voz narrativa en El Gran Vidrio parece demostrar un anhelo por la totalidad que, al expresarse en una pluralidad narrativa, se les escapa finalmente tanto a los narradores como a los lectores.

A nivel intertextual, las formas inmanentes-o las micrometanarrativas-operan de manera semejante en la narrativa de Bellatin. Como se ha mencionado antes, Morris señala que los elementos narrativos dispersos operan como micrometanarrativas o vestigios de una obra total, lo cual genera, según Martinetto, una "forma perversa de bricolaje que vuelve a lanzar el déjà vu en nuevos y cada vez más complejos circuitos de significación" (2012: 20). Las cuatro obras breves Underwood portátil. Modelo 1915, Escribir sin escribir, Giradores en torna a mi tumba y Disecado ponen de manifiesto cómo funciona ese pirateo narrativo. Retomando casi literalmente las reflexiones acerca de performances literarios que el narrador comparte en Underwood portátil. Modelo 1915, el texto Escribir sin escribir es una reelaboración del texto metapoético original. Disecado va un paso más allá: retoma tanto pasajes de Underwood portátil. Modelo 1915 y Escribir sin escribir como una reproducción literal del cuento Giradores en torno a mi tumba, que se publica también 
bajo forma independiente en el segundo tomo de la obra reunida de Bellatin. En suma, los mutantes, las prótesis, los perros, los personajes sufíes y las reelaboraciones de motivos de otras obras del "mundo bellatin" pueden leerse no como "artificios que no pretenden cuestionar ni significar nada más allá de sí mismos” (García Caballero 2011: 26) sino como manifestaciones inmanentes que apuntan a un todo transcendente que se nos elude finalmente.

El procedimiento de encadenar obras autorreferenciales aparece bajo forma condensada en Underwood portátil. Modelo 1915. En ese texto se yuxtaponen en párrafos alternados los siguientes elementos: 1) recuerdos sobre el libro sobre perros que escribió el alter ego de Mario Bellatin en su infancia, 2) afirmaciones metapoéticas sobre la novela Salon de belleza y el performance Congreso de dobles, 3) una serie de eventos que están en la base de la novela Perros héroes y 4) reflexiones sobre la conversión de Mario Bellatin al islam y su descubrimiento de la rama mística de esa religión. Al terminar un párrafo sobre el primer tema, se empieza uno nuevo que aborda el siguiente, y así sucesivamente, abriendo y cerrando los círculos al revisitar los temas que se habían empezado antes: 1, 2, 3, 4 - 1, 2, 3, 4- 1, 2, 3, 4 etc.

Este proceso encuentra eco en una de las muchas afirmaciones metapoéticas de Underwood portátil. Modelo 1915, donde el narrador declara que al releer sus textos, constata lo siguiente:

los diferentes textos estaban ubicados como círculos alrededor de determinados puntos. [...] Nunca los había leído juntos, ni había tenido jamás la intención de ensamblarlos. Sin embargo, fue mayor mi entusiasmo al advertir que una suerte de homogeneidad hacía posible que esa escritura, aparentemente dispersa, formara parte de un todo. (490-491)

Aunque no se establece la relación de manera explícita en el texto mismo, estos "círculos alrededor de determinados puntos" guardan una semejanza llamativa con una de las micrometanarrativas que abundan en la obra de Bellatin: la de la danza de los derviches giradores. En sus bailes, los derviches buscan evocar un simbolismo cósmico: según Muzaffer Ocak, el fundador turco de la orden Halveti-Yerráhi a la cual pertenece el propio Bellatin, la danza sufí muestra que todas las formas inmanentes de la que la creación está compuesta orbitan como partículas enamoradas alrededor de su núcleo divino u origen transcendente, que es Dios (Geels 1996: 240). De esa manera, la danza sufí no solo sirve como símbolo de la circumambulación perenne alrededor del Dios uno e incognoscible (Hirtenstein 1999: 6), sino también como metáfora del proyecto narrativo de Bellatin, donde "cada uno de los libros es un aspecto de un libro que [el narrador viene] redactando desde que era niño" (El registro de las flores, 266).

En el pensamiento de Ibn 'Arabi, la función de cada forma inmanente de la creación es "[to] supply God as a signified to every signifier, without ever being able to say what that 'God' is" (Almond 2004: 98). Aunque no está tan claro si se asigna todo significado a una instancia divina en la obra de Bellatin, sí parece que el punto al que apuntan los elementos narrativos no está tan vació como "[l]e centre [qui] n'est pas le centre" del pensamiento derrideano (Derrida 1967: 400). Esto se evidencia en El Gran Vidrio, cuando 
el narrador y un amigo sufí suyo hacen una "peregrinación, dando vueltas alrededor de una mezquita” (129). Sin embargo, no tienen "ninguna intención de ingresar" (130): los dos son peregrinos que dan vueltas alrededor de una verdad de la que saben que es últimamente inasequible. Como apunta el sociólogo Zygmunt Bauman, "[p]ara los peregrinos de todas las épocas, la verdad está en otra parte; el verdadero lugar siempre está distante en el tiempo y el espacio" ya que la "distancia entre el verdadero mundo y este mundo del aquí y ahora está constituida por la discordancia entre lo que debe alcanzarse y lo que se ha logrado" (2003: 43). Esto se ve reflejado en el comportamiento del narrador y su amigo: nunca alcanzan la verdad divina, lo cual no impide que sigan moviéndose alrededor de ella.

En el caso del narrador bellatiniano, esta circumambulación se evidencia no solo en la peregrinación alrededor de la mezquita sino también en escritos que tratan de estar "atento[s] al rumor del texto, a las reglas que pueden derivarse de su esencia [...] para que a partir de sus manifestaciones surjan sus verdaderas posibilidades" (El registro de las flores, 268). Dicho de otra manera, la narrativa bellatiniana sugiere que cada libro es la manifestación de una obra que recuerda una constelación mística que da vueltas alrededor de un centro transcendente. De eso se desprende que la totalidad bellatiniana parece guardar más semejanza con el concepto de wah.dat al-wujūd de Ibn 'Arabi que con el vacío derridiano. La totalidad propuesta en la obra de Bellatin es una que está fundamentada en una dialéctica entre lo uno y lo múltiple, abarcando todos los elementos ficcionales de la obra, que, aunque diferenciados y a primera vista fragmentados, apuntan al mismo origen elusivo, trazando "círculos alrededor de determinados puntos" en su circumambulación del misterio creativo.

La conexión de las letras y la creación continua

El siguiente pasaje de El Gran Vidrio sintetiza el pensamiento de Ibn 'Arabi a través de una reflexión alucinante sobre lo que hacen "los miembros de las comunidades sufíes en las estaciones de trenes o en los aeropuertos antes de abordar algún medio de transporte" (33). Exhibe más concretamente cómo el acto creativo conecta lo aparentemente disperso. Después de haber afirmado que "en la religión islámica, el milagro es un libro y nosotros somos sólo una letra de ese libro" (31), el narrador describe cómo los sufís buscan unirse los unos con los otros para llegar a formar una totalidad que les supera:

Es quizá ésa la razón, ser sencillamente una letra de un alfabeto infinito, por la que cuando algún practicante del sufismo se desplaza en avión o en tren acostumbra pasar por una serie de experiencias fuera de lo común. [...] [C] uando están a punto de abordar algún medio de transporte, sienten el [...] impulso de elegir, entre el grupo de desconocidos que suele poblar las salas, a alguna persona de la que nunca en la vida les gustaría desprenderse. Como una letra que buscara pegarse a otra para formar una palabra. (131)

Puede argumentarse que esta escena constituye una puesta en práctica del principio de wah. dat al-wujūd: sin perder la propia individualidad que la diferencia del otro, cada miembro de la comunidad sufí busca juntarse con un desconocido para llegar a formar parte de un todo, tal y como lo hacen las letras del alfabeto, que, como partículas bien diferenciadas fonética y ortográficamente, pueden juntarse para formar palabras. De esta manera, "una 
letra que busc[a] pegarse a otra para formar una palabra”, apunta de manera metonímica, al igual que las formas inmanentes de la creación en el pensamiento de Ibn 'Arabi, hacia algo más grande: a una palabra, a un texto, o incluso a toda la escritura, al libro total, que, para el Islam, equivale a la creación. En efecto, la reflexión en El Gran Vidrio sobre el afán del sufí de conectarse con el otro evoca un sueño descrito por Ibn 'Arabi en el cual éste sońaba que se casaba con las estrellas y las letras del alfabeto:

One night I saw myself united in marriage to all the stars of heaven, and I was married to each and every one with a most extraordinary spiritual joy. After I had been united to the stars, I was then given the letters of the alphabet and I was united in marriage to all of them, as individual letters and as joined others (Ibn 'Arabi en Hirtenstein 1999: 144).

Según Ibn 'Arabi, los elementos constituyentes de la creación son letras, y la creación entera corresponde al discurso de Dios (Hirtenstein 1999: 226). Según esta visión, el impulso creativo que conecta las letras dispersas es el nafas al-rah.mān, (el aliento divino de la compasión) (Hirtenstein 1999: 226, Mora Zahonero 2016: 34). Según Ibn 'Arabi, cuando Dios espira su compasión, las posibilidades que le son inherentes, simbolizado por las letras, son conectadas y convertidas en seres animados, que son, a su vez, simbolizados por las palabras. Así, una letra aislada constituye la posibilidad más sucinta de la expresión divina. Cuando las letras se combinan, forman palabras que expresan la intención divina de Dios, quien habla a través de ellas (Hirtenstein 1999: 226). Así, en esta escena de El Gran Vidrio, se muestra como el narrador-sufí busca juntarse con el otro para tratar de alcanzar el discurso eterno y total.

Basándose en el verso coránico que afirma que Dios "no cesa de crear" (C. 35:81) (citado en Mora Zahonero 2016: 32), Ibn 'Arabi sostiene además que todas las formas inmanentes de la creación se hallan sometidas a una perenne transformación (Chittick en Mora Zahonero 2016: 34). Según él, el aliento de Dios sigue soplando vida y significado en la creación, que es renovada continuamente: "a cada instante, el mundo en su totalidad es creado, destruido y recreado de nuevo". Como consecuencia de esta creación continua (Mora Zahonero 2016: 34), "cada criatura de Dios afronta un cambio de estado con cada respiración” (Ibn Arabi citado en Mora Zahonero 2016: 54). Dicho de otro modo, este afán de las letras de formar palabras con el fin de formar parte de un discurso divino implica un proceso creativo que siempre se renueva. Esto se ve reflejado en la obra de Bellatin, donde los elementos narrativos dispersos y las identidades de los narradores se retoman, siempre modificándose. Esto lo corrobora el narrador de El registro de las flores: "era consciente de que el ejercicio de creación estaba basado en un devenir constante.” (275).

Así, la obra de Bellatin, que ha sido caracterizada como una literatura mutante (Morris 2011: 102, Saenz 2012: 138, Palaversich 2003: 32-33) parece reclinar en el concepto de nafas al-rah.mān: al revisitar, retocar y remodelar sus micrometanarrativas, la totalidad elusiva que está subyacente a toda la obra, sopla un aliento creativo en la obra, conectando lo uno y lo múltiple. De esta manera, la narrativa de Bellatin lleva a cabo un proyecto que, en su esfuerzo por redactar obras que "son sólo puntos de referencia de la escritura en abstracto que los sostiene" (Registro de las flores, 273) contiene un elemento 
posiblemente blasfemo. A pesar de la supuesta adherencia a la doctrina islámica de muchos de los narradores de este universo literario, la obra bellatiniana parece una instancia divina que redacta una obra total compuesta de formas inmanentes. Esta obra se encuentra, tal y como la creación que es renovada y revitalizada a cada instante por el nafas al-rah.mān, en perenne transformación.

En este respecto, es significativo que Ibn 'Arabi extiende la noción de la creación continua a "la renovación permanente de los significados que debe acompañar a cada nueva lectura del Corán” (Mora Zahonero 2016: 52). Según el pensandor sufí, un lector del Corán que no capta un nuevo sentido cada vez que lee el texto sagrado, lo lee de manera errónea, puesto que "[e]l Corán es perpetuamente nuevo para aquellos que lo recitan" (Ibn 'Arabi Futūh.āt III.93-94 en Mora Zahonero 2016: 52). De manera análoga, la obra de Bellatin se abre a una multitud de lecturas que son generadas no por un vacío o una ausencia de la totalidad, sino por una concepción alternativa de la totalidad. Efectivamente, al afirmar la presencia simultánea de interpretaciones divergentes generadas por un centro elusivo, la narrativa bellatiniana busca situarse más allá de la dictadura de un significado único o vacío. Esto se hace posible por la incorporación de las nociones akbarís de wah. dat al-wujūd y nafas al-rah.mān, las cuales funcionan como principios constructores de la narrativa de Bellatin. La aparente fragmentación es renovada en cada instante por el soplo creativo que la engendra, conectando y revitalizando las letras, los elementos narrativos y las novelas individuales con el fin de conseguir un Libro Total.

\section{Conclusión}

El análisis de la función de los conceptos akbarís en la obra de Bellatin ha demostrado que su narrativa no rompe con la idea de la totalidad sino que remite a una concepción alternativa de ella. Rastreando las huellas del pensamiento sufí en la poética del escritor mexicano, se observa que el que una obra experimental juegue con nociones como la verdad, la totalidad y la transcendencia no implica que no pueda alimentarse de un pensamiento profundamente religioso. Así, el estudio de las funciones literarias del pensamiento sufí en esta obra moderna encaja en el reciente "turn to religion" en los estudios literarios, que se interesa por las interacciones entre las reflexiones literarias y las hermenéuticas escriturales (Allan 2013: 258). Respondiendo al interés recién avivado por la transcendencia, concepto anteriormente considerado como una reliquia anticuado de un pasado metafísico (Heinämäki et al. 2015), el análisis de la dialéctica entre lo uno y lo múltiple en la obra de Bellatin corrobora la observación de Héctor Hoyos de que la obra de Bellatin recombina referentes culturales para revelar trayectorias de intercambio inesperadas: "Bellatin challenges our understanding of cultural referents [...], constantly recombining them to reveal unexpected trajectories in global cultural exchange" (2015: 182). En efecto, apropiando conceptos místicos que tienen su origen en el contexto islámico del siglo XII, la obra de Bellatin "reveal[s] the affinities between cultural artefacts that we often ascribe to utterly different categories" (Hoyos 2015: 182), en este caso las categorías de una poética latinoamericana experimental y de la mística islámica. Como se ha mostrado, una lectura resistente a la idea de la totalidad tiene un punto ciego para la afinidad que tiene la obra de Bellatin con el referente cultural supuestamente ajeno que es la mística islámica, y por tanto tendrá dificultades a examinar las aspiraciones transcendentes de su narrativa. 
En cambio, una lectura que aborda su obra en clave comparativa con un pensamiento místico muestra que sus textos invitan una multitud de interpretaciones que no tienen sus raíces en un vacío, sino en una totalidad determinada por la relación entre lo inmanente y lo transcendente. Así, al dejarse sorprender por el movimiento continuo de "círculos alrededor de determinados puntos," el lector de la narrativa de Bellatin puede vislumbrar "la silueta del derviche" que, "a pesar de encontrarse presente, [...] casi desaparec[e]", dejando solo "la estela fugaz de un movimiento sin fin" (499).

\footnotetext{
Notas

${ }^{1}$ Un estudio sobre la historia del sufismo en la literatura latinoamericana queda por escribirse. Un paso preparatorio podría encontrarse en la obra de Luce López-Beralt, que ha investigado la presencia del imaginario islámico en la literatura española. López Baralt, Luce. Huellas del Islam en la literatura española: de Juan Ruiz a Juan Goytisolo. Madrid: Hiperión, 1989.

${ }^{2}$ No obstante, el Islam sí está presente en Latinoamérica. Un estudio interesante al respecto es Crescent over Another Horizon (2015).

${ }^{3}$ La Comunidad El Nur-Ashki-Yerráhi forma parte de la red transnacional de la orden Helveti-Jerráhi cuyos origines se sitúan en Estambul, Turquía, donde fue fundada en el siglo XI (Geels 1996: 231, Hermansen 2006: 30). La orden se introdujo en los Estados Unidos por Shaykh Muzaffer Ozak (1916-1993) en los 1980s (Geels 1996: 231, Hermansen 2006: 30). Más tarde se abrió una mezquita de los Helveti-Jerráhi en México D.F, dirigida por la sheika Amina Teslima al-Yerráhi (Edlín Ortiz Graham). Un análisis de la obra de Mario Bellatin dentro del contexto del sufismo transnacional y sus relaciones con la literatura neosufí, la literatura latinoamericana y la literatura mundial requiere un estudio aparte. Se puede encontrar más información sobre el Islam en México en Pastor de María y Campos (2015). Enlace a la página de la orden Helveti-Jerráhi en México: http://www.sufimexico.com/.

${ }^{4}$ https://www.facebook.com/bellatin?ref=br_rs.

5 "The Writer's Block Transcripts: A Q\&A with Mario Bellatin” The Sampsonia Way: An Online Magazine for Literature, Free Speech and Online Justice. 25 de abril 2016. http://www.sampsoniaway.org/ interviews/2016/04/25/the-writers-block-transcripts-a-qa-with-mario-bellatin/.

${ }^{6}$ Por otro lado, el mismo estudio sostiene que el sufismo es una doctrina que sostiene que "toda la humanidad es una sola" y para la que no existen divisiones entre lo humano y lo divino ni "cosas diferenciadas o separadas salvo en apariencia y a un nivel de superficie" (Martínez 2011: 236). Tales afirmaciones corren el riesgo de calificar el sufismo como una doctrina panteísta, lo cual no lo es en absoluto (Hirtenstein 1999: 24).

7 “Entrevista con Mario Bellatin: Ciclo Babelia." El País. 27 junio 2012. http://cultura.elpais.com/ cultura/2012/06/27/actualidad/1340812800_1340822039.html

8 "When a person rationally considers God, he creates what he believes in himself through his consideration. Hence he considers only a god that he has created through his consideration" (Ibn 'Arabi, Fusûs al-hikam, traducido por Ralph Austin y citado en Almond 2004: 15).

${ }^{9}$ Adjetivo referente al epiteto de Ibn 'Arabi, el Shaykh al-Akbar (el maestro más grande).

${ }^{10}$ Los capítulos enfocan entre otras cosas el trayecto embriagado de un escritor sufí, la agitación provocada por una relación fracasada, y las consecuencias desastrosas de un experimento médico.

${ }^{11} \mathrm{El}$ narrador ofrece una traducción incorrecta del nombre árabe; 'Abdus al-Salam' significa 'el sirviente de la paz' ('el hijo de la paz' se traduciría por 'Ibn al-Salam').

${ }^{12}$ Refiriéndose a Flores, Palaversich sostiene que "los nombres e identidades se deslizan unos sobre otros en un juego complejo donde toda unidad del ser está perdida” (2003: 33).
}

\section{Bibliografía}

Allan, Michael. "Reading Secularism: Religion, Literature, Aesthetics." Comparative Literature 35.3 (2013): 257-264.

Almond, Ian. Sufism and Deconstruction: A Comparative Study of Derrida and Ibn Arabi. London: Routledge Studies in Religion, 2004.

Arias, Martín. "Islam/sufismo" en Abecedario Bellatin [dossier], Carlos Walker, ed. Mil hojas. Formas de la literatura contemporánea. Santiago de Chile: Hueders, 2017, 364-369. 
Bauman, Zygmunt. "De peregrino a turista, o una breve historia de la identidad" en Cuestiones de identidad cultural, ed. Stuart Hall, Paul du Gay, trad. Horacio Pons. Buenos Aires: Amorrortu, 2003, 40-68.

Bellatin, Mario. "Flores" en Obra reunida. Madrid: Alfaguara, 2005.

Bellatin, Mario. "Underwood portátil. Modelo 1915” en Obra reunida. Madrid: Alfaguara, 2005.

Bellatin, Mario. "Disecado" en Obra reunida 2. México D.F.: Alfaguara, 2014.

Bellatin, Mario. "El Gran Vidrio: tres autobiografías" en Obra reunida 2. México D.F.: Alfaguara, 2014.

Bellatin, Mario. "El registro de las flores" en Obra reunida 2. México D.F.: Alfaguara, 2014.

Bellatin, Mario. "Escribir sin escribir" en Obra reunida 2. México D.F.: Alfaguara, 2014.

Bellatin, Mario. "Giradores en torno a mi tumba" en Obra reunida 2. México D.F.: Alfaguara, 2014.

Bize, Gustavo C. "Ibn 'Arabi y el papel de la literatura en el sufismo: un análisis de su obra La disertación de los piadosos." Azufre rojo. Revista de estudios sobre Ibn 'Arabi 3 (2016): 55-88.

Carlsen, George. "Evoking Japan in Mario Bellatín’s Cosmopolitan Novels.x El jardín de la señora Murakami and Shiki Nagaoka: Una nariz de ficción." Confluencia: Revista Hispánica de Cultura y Literatura 31.1 (2015): 67-77.

Derrida, Jacques. Écriture et la Différance. Paris: Seuil, 1967.

Epplin, Craig. "Mario Bellatin y los límites del libro" en Julio Ortega y Lourdes Dávila, eds. La variable Bellatin. Navegador de lectura de una obra excéntrica. Veracruz: Universidad Veracruzana, 2012, 99-117.

García Caballero, Herminio: "Mario Bellatin: la literatura travesti." El Coloquio de los Perros. Revista de Literatura. "Mario Bellatin: el experimento infinito" (2011), http://www.elcoloquiodelosperros.net/ numerobellatin/beher mi.html.

Geels, Antoon. "A Note on the Psychology of Dhikr: The Halveti-Jerrahi Order of Dervishes in Istanbul." The International Journal for the Psychology of Religion 6.4 (1996) 229-251.

Heinämäki, Elisa, Mehtonen, P.M., Salminen, Antti. The Poetics of Transcendence. Amsterdam: Rodopi, 2015.

Hermansen, Marcia "Literary production of Western Sufi movements" en Sufism in the West. Malik, Jamal; Hinnells, John, ed. London: New York: Routledge, 2006.

Hermosilla Sánchez, Alejandro "Mario Bellatin: una literatura perversa y narcisista." El Coloquio de los Perros. Revista de Literatura. "Mario Bellatin: el experimento infinito" (2011), http://www. elcoloquiodelosperros.net/numerobellatin/beher mi.html.

Hirtenstein, Stephen. The Unlimited Mercifier: The spiritual life and thought of Ibn 'Arabī, Anqa Publishing, Oxford, 1999.

Hoyos, Héctor. Beyond Bolaño: The Global Latin American Novel. New York: Columbia University Press, 2015.

López Alfonso, Francisco José. “Mario Bellatin.” en The contemporary Spanish-American novel: Bolaño and after. en Wilfrido Corral, Nicholas Birns, Juan De Castro, eds. New York: Bloomsbury Academic, 2013, 23-30.

López Alfonso, Francisco José. "Laberintos en "La enfermedad de la sheika," de Mario Bellatin." Romance Notes 55. 2 (2015): 265-271.

López Alfonso, Francisco José. Mario Bellatin, el cuadernillo de las cosas difíciles de explicar. Cuadernos de América sin nombre 37. Alicante: Publicaciones de la Universidad de Alicante, 2015.

Martinetto, Vittoria. "Palimpsestos en el universo Bellatin" en Julio Ortega, Lourdes Dávila, eds. La variable Bellatin. Navegador de lectura de una obra excéntrica. Veracruz: Universidad Veracruzana, 2012, 15-33.

Martínez Caballero, Óscar. "La vertiente barroca de la literatura de Mario Bellatin" El Coloquio de los Perros. Revista de Literatura. "Mario Bellatin: el experimento infinito" (2011), http://www. elcoloquiodelosperros.net/numerobellatin/beher mi.html.

Martínez, Aurora. "Sufismo, misticismo y artificio en la literatura de Mario Bellatin" El Coloquio de los Perros. Revista de Literatura. "Mario Bellatin: el experimento infinito" (2011), http://www. elcoloquiodelosperros.net/numerobellatin/beher mi.html.

Mora Vicente, Luis "Las mutaciones mórbidas: el espejo y la muerte en la obra de Mario Bellatin" en Julio Ortega, Lourdes Dávila, eds. La variable Bellatin. Navegador de lectura de una obra excéntrica. Veracruz: Universidad Veracruzana, 2012, 71-98.

Mora Zahonero, Fernando. "Creación continua: "el abandono de toda certeza" Azufre rojo. Revista de estudios sobre Ibn Arabi 3 (2016): 30-54.

Morris, Adam. "Micrometanarratives and the Politics of the Possible." The New Centennial Review 11.3 (2011), pp. 91-117. 
Neyra, Ezio. "No hay más escritura que la escritura". Entrevista a Mario Bellatin" en Julio Ortega, Lourdes Dávila, eds. La variable Bellatin. Navegador de lectura de una obra excéntrica. Veracruz: Universidad Veracruzana, 2012, 207-219.

Ohlander, Erik S. "Early Sufi Rituals, Beliefs, and Hermeneutics." en The Cambridge Companion to Sufsm. Lloyd Ridgeon, ed. New York: Cambridge University Press, 2015. 53-3.

Pastor de María y Campos, Camila. "Guests of Islam: Conversion and the Institutionalization of Islam in Mexico." in Crescent over Another Horizon: Islam in Latin America, the Caribbean and Latino USA, María Logroño Narbona Del Mar, Paulo Pinto, Tofik Karam, John Austin, eds. University of Texas Press, 2015, pp. 144-189.

Palaversich, Diana. "Apuntes para una lectura de Mario Bellatin." Chasqui. Revista de Literatura Latinoamericana, 32.1 (2003): pp. 25-38.

Pitois-Pallares, Veronique. Sous le signe du je: pratiques introspectives dans le roman mexicain (2000-2010). Université Paul Valéry-Montpellier III, 2015.

Ridgeon, Lloyd. "Preface." en The Cambridge Companion to Sufism. Lloyd Ridgeon, ed. New York: Cambridge University Press, 2015. xv-xvi.

Saénz, Inés. "Hacer zapping de sí mismo: Bellatin y el yo hipermoderno." en Julio Ortega y Lourdes Dávila, eds. La variable Bellatin. Navegador de lectura de una obra excéntrica. Veracruz: Universidad Veracruzana, 2012, 135-161.

Vecchio, Diego. "Islam/sufismo" en Abecedario Bellatin en Carlos Walker, ed. Mil hojas. Formas de la literatura contemporánea. Santiago de Chile: Hueders, 2017, 394-400. 